\title{
Benefícios do trabalho entre pares para a aprendizagem matemática do sujeito com Síndrome de Down
}

\author{
Benefits of peer work for the mathematical learning of the subject with Down's Syndrome \\ Los beneficios del trabajo entre pares para el aprendizaje matemático del sujeto con Síndrome de
}

Down

Recebido: 18/09/2021 | Revisado: 23/09/2021 | Aceito: 24/09/2021 | Publicado: 26/09/2021

\author{
Gisély de Abrêu Corrêa \\ ORCID: https://orcid.org/0000-0002-3482-955X \\ Colégio Marista Nossa Senhora da Penha, Brasil \\ E-mail: giselyacorrea@gmail.com \\ Guilherme Augusto Maciel Ribeiro \\ ORCID: https://orcid.org/0000-0002-8633-089X \\ SEDU/ES, Brasil \\ E-mail: gamribeiro@gmail.com \\ Edmar Reis Thiengo \\ ORCID: https://orcid.org/0000-0002-4423-4939 \\ Instituto Federal do Espírito Santo, Brasil \\ E-mail: thiengo.thiengo@gmail.com
}

\begin{abstract}
Resumo
Os estudantes com síndrome de Down fazem parte do público-alvo da Educação Especial, com direito à escola regular e atendimento especializado. Mais do que a permanência na escola, esses alunos têm garantia de aprendizagem e permanência na escola, o que indica um avanço na legislação a esse respeito. Para que a inclusão ocorra de fato, é necessário que a escola se adapte às necessidades desses sujeitos, e não o contrário. A aprendizagem matemática é tão importante quanto a aprendizagem da leitura e da escrita para garantia da inclusão. Foi realizado um estudo de caso único com um estudante com síndrome de Down cursando a terceira série do Ensino Fundamental de uma escola da rede particular de ensino. O presente artigo tem por objetivo analisar os resultados do trabalho entre pares para a aprendizagem matemática de uma criança com síndrome de Down, utilizando o jogo Ganha 100 primeiro, adaptado a partir da teoria da formação planejada das ações mentais e dos conceitos.
\end{abstract}

Palavras-chave: Síndrome de Down; Aprendizagem matemática; Jogos; Teoria da formação planejada das ações mentais e dos conceitos.

\begin{abstract}
Students with Down's Syndrome are part of the target audience of Special Education, with the right to regular school and specialized care. More than staying in school, these students are guaranteed to learn and stay in school, which indicates an advance in legislation in this regard. For inclusion to actually occur, it is necessary that the school adapts to the needs of these subjects, and not the other way around. Learning mathematics is as important as learning to read and write to ensure inclusion. A single case study was carried out with a student with Down syndrome attending the third grade of elementary school at a private school. This article aims to analyze the results of work among peers for the mathematical learning of a child with Down syndrome, using the game Win 100 first, adapted from the Theory of Planned Formation of Mental Actions and Concepts.
\end{abstract}

Keywords: Down's syndrome; Math learning; Games; Theory of planned formation of mental actions and concepts.

\section{Resumen}

Los estudiantes con síndrome de Down forman parte del público de Educación Especial, con derecho a una escuela regular y atención especializada. Más que permanecer en la escuela, estos estudiantes tienen la garantía de aprender y permanecer en la escuela, lo que indica un avance en la legislación en este sentido. Para que la inclusión se produzca realmente es necesario que la escuela se adapte a las necesidades de estas asignaturas y no al revés. Aprender matemáticas es tan importante como aprender a leer y escribir para garantizar la inclusión. Se realizó un estudio de caso único con un estudiante con síndrome de Down que cursaba el tercer grado de la escuela primaria en una escuela privada. Este artículo tiene como objetivo analizar los resultados del trabajo entre pares para el aprendizaje matemático de un niño con síndrome de Down, utilizando el juego Win 100 first, adaptado de la teoría de la formación planeada de las acciones mentales y de los conceptos. 
Palabras clave: Síndrome de Down; Aprendizaje matemático; Juegos; Teoría de la formación planeada de las acciones mentales y de los conceptos.

\section{Introdução}

A Educação Especial, no Brasil, "tem sido considerada como educação de pessoas com deficiência, seja ela mental, auditiva, visual, motora, física múltipla ou decorrente de distúrbios evasivos do desenvolvimento, além das pessoas superdotadas que também têm integrado o alunado da educação especial” (Rogalski, 2010, p. 3). Em seus aspectos históricos, conforme nos aponta Sassaki (2012), ela atravessou diferentes paradigmas rumo a efetiva garantia de direito à escolarização das pessoas com deficiência: a fase da exclusão, fase da institucionalização, fase da integração e a fase da inclusão.

Na observância de estudiosos como Mendes (2010), Mazzotta (2011) e Silveira e Drago (2010), cada uma dessas fases revela o entendimento à época sobre o processo de escolarização de alunos com deficiências, processo que se inicia no século XIX e que perdura até os dias atuais, estando atrelado às demandas sociais, políticas e econômicas vigentes, sobretudo àquelas originadas pelas reinvindicações dos movimentos populares (Michels \& Lehmkuhl, 2016).

Nos termos da legislação vigente, a Constituição Federal Brasileira e a Lei de Diretrizes e Bases da Educação Nacional (Lei. $\mathrm{N}^{\circ}$ 9.394/1996, alterada posteriormente pela Lei $\mathrm{n}^{\circ} 12$. Lei 12.796/2013) asseguram um atendimento educacional especializado para os alunos com deficiência, sobretudo no que regimenta os artigos nº 58, 59 e 60 da Lei n 12 . Lei 12.796/2013, cujas orientações sinalizam para a oferta de um ensino pautado pela inclusão, acesso e a permanência desses estudantes nos ambientes formais de ensino, sem haver qualquer distinção quanto ao direito de escolarização, embora salvaguardadas as especificidades demandadas pelas necessidades educacionais específicas de cada um. Trata-se de conquistas ainda em campo de disputas e reafirmações no cenário nacional e que desvelam para a necessidade de novas reformulações políticas, pedagógicas e estruturais com vistas a garantir a efetividade do processo de inclusão.

Embora reconhecida no cenário educacional, a educação da pessoa com deficiência ainda figura como um desafio ao trabalho docente, mesmo contando com os avanços significativos no âmbito educacional. Isso porque mesmo após a Convenção de Guatemala e a promulgação, no Brasil, do Decreto 3.956 em 8 de outubro de 2001, que disciplina a eliminação de todas as formas de discriminação por razões de deficiências, algumas unidades escolares brasileiras ainda não se adequaram devidamente para a efetivação da inclusão de alunos com necessidades educacionais específicas nas escolas regulares, do mesmo modo que, ainda, não se observam em alguns espaços escolares a devida qualificação profissional docente para atender a essa demanda educativa tão singular.

Nos estudos de Silva (2015) o desafio para a inclusão no cotidiano escolar implica na reformulação das propostas político-pedagógicas dos cursos iniciais de formação docente, na readequação das políticas públicas educacionais, assegurando o efetivo direito à escolarização, com a adaptação dos currículos escolares às necessidades educacionais dessa clientela, na estruturação física e humana dos ambientes escolares, com recursos pedagógicos e profissionais especializados para o devido atendimento à pessoa com deficiência.

Considerando que a aprendizagem dos estudantes público-alvo da Educação Especial seja possível e que o ambiente escolar deve oferecer condições adequadas para o desenvolvimento de situações de aprendizagem para esses sujeitos, aceitamos a hipótese de que a aprendizagem entre pares seja uma potente possibilidade pedagógica para a construção de conhecimentos e significados por alunos com a Síndrome de Down. No entanto, recorremos aos conceitos de Zona de Desenvolvimento Proximal (ZDP) proposto por Lev Semenovitch Vigotski e da Teoria da Formação Planejada das Ações Mentais e dos Conceitos de Galperin (2013), para discutir possibilidades para a aprendizagem do sujeito com Síndrome de Down a partir dos resultados da pesquisa realizada por Corrêa (2017) no que se refere aos benefícios do trabalho entre pares para aprendizagem matemática do sujeito com Síndrome de Down. 


\section{O estudante com Síndrome de Down Características e Implicações para a Aprendizagem Matemática}

Nos processos inclusivos, o ambiente escolar recebe uma diversidade de alunos público-alvo da educação especial, entre eles aqueles que possuem Síndrome de Down. Garantir condições para que tais sujeitos possam aprender não é algo simples. É necessário que todo o sistema educacional seja reestruturado, de modo que os sujeitos com a Síndrome de Down se sintam acolhidos. Não cabe a esses alunos a tarefa de se integrar à escola, mas o contrário: é a escola que tem a obrigação de se estruturar para recebê-los e promover o desenvolvimento possível para cada um deles.

Do ponto de vista médico, é preciso compreender as especificidades orgânicas dos sujeitos com Síndrome de Down. Schwartzan afirma que

A síndrome de Down é uma alteração genética que ocorre durante a divisão meiótica do embrião e causa alterações cromossômicas, através de um erro na distribuição, as células recebem 1 cromossomo a mais ligados ao par 21. Existem três tipos de síndrome de Down, são eles:- Trissomia simples - quando são observados três cromossomos no par 21 em todas as células do indivíduo, ou seja, a pessoa tem 47 cromossomos, ao invés de 46, que é o normal - Translocação observa-se a Trissomia, mas nem todos os cromossomos trissômicos estão no par 21, às vezes, o cromossomo extra se apresenta em outros pares, n. 14 ou 22 - Mosaico - na divisão do óvulo fecundado, algumas células ficam com 47, outras com 46 cromossomos (Schwartzan, 1999, p. 98).

Apesar dessa condição congênita, Bissoto (2005) evidencia que existem possibilidades de aprendizagem por parte destes, e destaca que todas as atividades educacionais ou terapêuticas devem ser vistas como ímpares para cada indivíduo, já que ele é fruto de condições genéticas, socioculturais e históricas nos contextos sociais, educativos e familiares.

Mento et al. (2020) destacaram a presença de diferentes níveis de deficiência intelectual entre os sujeitos, bem como um perfil documentado de outras deficiências, como a habilidade verbal prejudicada, a memória de trabalho e a flexibilidade, comparando com sujeitos de desenvolvimento típico. Registraram também a presença das habilidades visuoespaciais preservadas. Castro e Drago (2013) ao discorrerem sobre inclusão na sala de aula regular, destacam que é fundamental observar as características físicas e cognitivas oriundas da síndrome de Down “[...] para desvelar as possibilidades de trabalho pedagógico levando em consideração o indivíduo como um todo, para assim fomentar estratégias de estímulos eficazes como foco na inclusão desses sujeitos" (Castro \& Drago, 2013, p. 79).

Entre os fatores que facilitam o aprendizado indicado pelos autores, está a habilidade visual e a capacidade de imitação de comportamentos e atitudes das outras pessoas, o que indicaram como uma forma positiva de aprendizado e chamaram de aprender com os pares (Castro \& Drago, 2013). Estas habilidades foram consideradas por Corrêa (2017) como fundamentais para a realização da pesquisa sobre a apropriação do conceito de sistema de numeração decimal por uma criança com Síndrome de Down.

O processo de aprendizagem da pessoa com Síndrome de Down precisa estar centrado no sujeito e não deve ser conjecturado sobre expectativas do ponto de vista docente ou familiar. As especificidades dos sujeitos com Síndrome de Down devem constituir o ponto de partida para a promoção de situações de aprendizagem e não se encerrar nas sinalizações que evidenciam obstáculos, ao contrário, devem constituir elementos potentes para desenvolver estratégias e promover os avanços desses indivíduos.

\section{Caminhos para a Aprendizagem Matemática do Sujeito com Síndrome de Down: os jogos}

Os autores do caderno três do Programa de Alfabetização na Idade Certa (PNAIC) (Brasil, 2014), voltado para a construção do Sistema de Numeração Decimal (SND), destacam a importância dos jogos para a construção da consciência numérica, que ocorrerá quando a criança consegue operar com os números, reconhecendo as propriedades do Sistema de 
Numeração Decimal. O referido caderno apresenta propostas para que as crianças se apropriem desse sistema (Vianna, 2014), sendo a exploração do corpo "[...] uma das práticas mais importantes para a construção do número pela criança, pois, contando nos dedos, as crianças começam a construir uma base simbólica que é essencial neste processo [...]” (Muniz et al., 2014, p. 10). O acesso a materiais manipuláveis, palitos, sementes, tampinhas, miçangas, fichas e outras possibilidades, em situações de quantificação também oferece importante contribuição. Os autores apresentam o quanto os jogos fornecem recursos para a aprendizagem e destacam a importância da mediação do professor para a proposição daqueles que levem à aprendizagem matemática e a manutenção do seu caráter lúdico, escolhendo os que sejam interessantes para os estudantes.

O jogo apresenta diversas possibilidades, pois trata-se de uma "[...] atividade didática realizada a partir de um material pedagógico, na qual as regras são definidas para garantir a realização de certas aprendizagens matemáticas" (Muniz et al., 2014, p. 39). Oportunamente, o uso de materiais manipulativos (MM) é defendido pela literatura acadêmica em Passos (2004, p. 5) quando discorre que "[...] os materiais manipuláveis são objetos ou coisas que o aluno é capaz de sentir, tocar, manipular e movimentar. Podem ser objetos reais que têm aplicação no dia-a-dia ou podem ser objetos que são usados para representar uma ideia." No tocante ao contexto da aprendizagem matemática por alunos com Síndrome de Down, é notável que os MM constituem recursos físicos estimulantes, capazes de auxiliar na apropriação dos conteúdos matemáticos por estudantes em diversos níveis de aprendizagem, sejam eles neurotípicos ou com necessidades educacionais específicas. Isso porque durante a sua utilização, observa-se o compartilhamento e a troca de experiências entre os pares, favorecendo a habilidade criadora e do convívio entre eles, o que reafirma a perspectiva de uma educação verdadeiramente inclusiva.

Nessa perspectiva, o jogo Ganha 100 primeiro, parte do caderno três do PNAIC, emerge como uma possibilidade de estimulação da aprendizagem matemática, tendo sido escolhido para o trabalho com o estudante com Síndrome de Down, como etapa inicial para a apropriação do conceito de número e realização de agrupamentos, conceitos básicos que antecedem a compreensão do SND, como observado na Figura 1.

Figura 1- Jogo Ganha 100 primeiro

\begin{tabular}{|l|}
\hline \multicolumn{1}{|c|}{ GANHA 100 PRIMEIRO } \\
Objetivo geral de aprendizagem \\
Construção da noção de agrupamento de 10 em 10. \\
Habilidades: \\
Espera-se, com este jogo, que o estudante seja capaz de: \\
- Selecionar a quantidade de palitos, a partir da indicação dos dados; \\
• Contar de um em um; \\
- Relacionar número e quantidade; \\
- Comparar quantidades, atribuindo o conceito muito ou pouco, a partir \\
das dezenas; \\
- Agrupar palitos de 10 em 10; \\
- Contar de 10 em $10 ;$ \\
• Formar grupos de 100 a partir do agrupamento das dezenas.
\end{tabular}

Fonte: Corrêa, (2017, p. 75).

Outro aspecto determinante para a escolha do jogo Ganha 100 primeiro como recurso para desenvolver habilidades matemáticas, como mostra a Fgura 1, foi que ganhar o jogo não depende do desenvolvimento intelectual dos participantes.

Ganha aquele jogador que obtiver 100 palitos primeiro, resultado alcançado através dos dados. São os números 
aleatoriamente indicados pelos dados que determinarão quem pega mais palitos. Dessa forma, todos possuem as mesmas possibilidades de ganhar, seja o estudante com deficiência intelectual causada pela Síndrome de Down, ou os demais colegas de desenvolvimento típico. As regras do jogo já estabeleceram condição de igualdade, mesmo com as diferenças entre os jogadores.

O trabalho com jogos, objetivando o desenvolvimento de habilidades matemáticas, também foi escolhido pelo caráter lúdico que envolve esse tipo de recurso e por oferecer possibilidades de aprendizagem entre pares. Como a principal pergunta de Galperin objetivava descobrir como as habilidades podiam ser adquiridas no processo de ensino, Corrêa e Thiengo (2017) adaptaram o jogo Ganha 100 primeiro, para apropriação do conceito de número e do agrupamento por dezenas para crianças com Síndrome de Down, utilizando a Teoria da Formação Planejada das Ações Mentais e dos Conceitos.

É importante destacar que a utilização dos materiais manipulativos dialoga com a perspectiva da aprendizagem entre pares, sendo estes ancorados pela aprendizagem mediada descrita por Vigotski (2007). Não obstante, a compreensão sobre a epistemologia psicogenética vigotskiana e suas imbricações sociointeracionistas constituem elementos inerentes às atividades docentes, sobretudo para a promoção de situações de aprendizagens matemáticas, inclusive com a intermediação de materiais manipulativos ou da interação mediada entre pares.

Nos estudos de Vigotski, “[...] a discrepância entre a idade mental real de uma criança e o nível que ela atinge ao resolver problemas com o auxílio de outra pessoa indicam a zona do seu desenvolvimento proximal" (Vigotski, 2005, p. 129). Em outras palavras, a zona de desenvolvimento proximal (ZDP) marca a distância entre o nível de desenvolvimento real (aquilo que identifica o que a criança consegue fazer sozinha) e o nível de desenvolvimento potencial (aquilo que ela necessita de auxílio para conseguir realizar). Dessa forma, a ZDP determinará as possibilidades de aquisição de aprendizagem da criança. A despeito da aprendizagem entre pares e sua interlocução da perspectiva sociointeracionista, "[...] o que a criança é capaz de fazer hoje com cooperação, será capaz de fazer sozinha amanhã. Portanto, o único tipo positivo de aprendizado é aquele que caminha à frente do desenvolvimento, servindo-lhe de guia" (Vigotski, 2005, p. 129-130).

\section{Galperin e a Formação Planejada das Ações Mentais e dos Conceitos}

O psicólogo soviético Piotr Yakovlevich Galperin (1902-1988) foi responsável por várias pesquisas na Universidade de Moscou durante mais de trinta anos. Trabalhou com Leontiev, em continuidade ao trabalho de Vigotski, e seu foco de estudos voltou-se para o ensino. Embora a teoria não seja objeto principal deste artigo, é importante destacar alguns aspectos, entre eles o reconhecimento de que antes de um conceito transformar-se em um ato mental, ele parte de uma ação material do sujeito sobre o objeto de estudo. "As experiências de Galperin demonstraram o processo de formação de novas estruturas e qualidades do pensamento do estudante e de como ele se apropria simbolicamente da atividade social" (Corrêa, 2017, p. 48).

A ideia fundamental da Teoria da Formação Planejada das Ações Mentais e dos Conceitos, por sua natureza, são ações objetivas que, inicialmente, se realizam com o apoio de objetos externos na medida em que estes são manipulados [...]. Posteriormente, as ações são realizadas no plano mental e se tornam propriedade da psique [...] (Núñez \& Ramalho, 2017, p. 5).

Núñez e Ramalho (2017), estudiosos da teoria de Galperin, explicam que há mudança de estágio da atividade mental, que acontece em novo plano e com novas formas de pensamento. Durante a formação dessas ações internas, Galperin distingue quatro etapas fundamentais:

A formação da base orientadora da nova ação (BOA), quando a ação é preparada e constitui-se na representação antecipada da tarefa, constando todas as orientações para a ação futura. Nesta etapa é fundamental que o estudante, além de compreender o que será realizado, esteja motivado para tal.

Em seguida parte-se para a formação do aspecto material dessa ação, quando o sujeito age externamente sobre os 
objetos. Um exemplo da diminuição dessa ação externa refere-se à contagem. Para contar o sujeito agrupa os objetos, em seguida apenas toca-os, para finalmente apenas lançar os olhos sobre eles (Galperin, 2013).

A diminuição da ação material marca a etapa seguinte, que é a formação de seu aspecto linguístico. Aqui a ação verbal comunica a ação material, gradativamente vai se liberando da ação com as coisas, até chegar a "ação por fórmula", quando o conceito passa a ser utilizado em diferentes situações.

O aspecto sonoro vai diminuído até chegar no que Galperin chama de "falar para si", que não representa uma forma de comunicação com o outro, e sim uma estratégia para auxiliar o próprio pensamento (Galperin, 2013), iniciando a formação dessa ação como um ato mental.

\section{Metodologia}

A pesquisa foi realizada em uma turma de terceira série do Ensino Fundamental de uma escola regular da rede particular de ensino, envolvendo um estudante com Síndrome de Down, na época com 11 anos, e dois outros estudantes de desenvolvimento típico da mesma sala, todos devidamente autorizados por suas famílias.

A metodologia utilizada foi o estudo de caso único, sem pretensão de generalizar os resultados, mas compreender os fatos na medida e no contexto em que aconteceram. De acordo com Gil (2009), o fenômeno ocorre no momento da pesquisa e sua análise foi considerada a partir do contexto.

Os dados foram produzidos a partir de entrevistas por pautas e informais realizadas com a professora, com a monitora, com a mãe do sujeito principal da pesquisa, além da observação participante em sala de aula e análise dos seus materiais produzidos nas aulas de Matemática. As fotografias, gravações de áudio e o diário de notas foram ferramentas importantes para os registros utilizados durante as observações. Inicialmente pretendeu-se realizar os registros através de filmagens, mas como o equipamento distraiu o estudante, esse recurso foi descartado.

\subsection{O ambiente de pesquisa}

A pesquisa foi realizada em uma escola da rede particular de ensino, com um estudante com síndrome de Down, cursando a $3^{\text {a }}$ série do ensino fundamental, na época com 11 anos, o qual chamaremos de Marcos, para preservar sua identidade. Participaram do estudo dois outros estudantes de desenvolvimento típico, ambos da mesma turma e todos devidamente autorizados por seus responsáveis. Marcos possuía uma monitora que o acompanhava em todas as atividades escolares.

Marcos sentava-se no fundo da sala, ao lado de sua monitora que o auxiliava em todas as orientações direcionadas pela professora. Como faz parte do trabalho com crianças que elas também aceitem participar da pesquisa, além de autorizadas por seus pais, ao explicar para a turma que algumas atividades matemáticas seriam realizadas com Marcos e perguntar quem gostaria de participar de alguns desses momentos, todos os colegas da turma demonstraram interesse. A pesquisadora observou um ambiente de afetividade entre as outras crianças e Marcos, indicação de que os colegas desejavam estar perto e interagir com ele.

Algumas atitudes agressivas de Marcos foram observadas em relação às crianças da sala. Mesmo assim, elas não deixavam de se aproximar dele, o que gerava reação da professora, como registrado pela pesquisadora quando um dos colegas, identificado aqui como André, aproximou-se da mesa de Marcos e levou um tapa dele. "Já não falei pra vocês, André, que não pode chegar perto do Marcos" (Corrêa, 2017, p. 71).

Segundo a professora, fato que foi confirmado pela mãe, Marcos bate nos colegas sem nenhum motivo aparente. Em nossa percepção, a orientação da professora de que as crianças não poderiam chegar perto dele teve a intenção de proteger, de garantir que ninguém sofresse alguma agressão por parte de Marcos (Corrêa, 2017, p. 71).

Esse dado revelado durante a coleta de dados trouxe maior atenção da pesquisadora para a atividade que seria proposta, a realização do jogo Ganha 100 primeiro. O trabalho entre pares estava previsto na proposta de trabalho, considerando as 
interações sociais como aspecto necessário ao aprendizado, como asseverava Vigostski através abordagem histórica e cultural. Quando Vigostski estabelece uma nova forma de identificar o nível de desenvolvimento das crianças, observou que a execução de tarefas em cooperação possibilitavam a realização de atividades que individualmente eram muito difíceis para serem cumpridas, indicando a zona de desenvolvimento potencial (ZDP), pois "O nível de desenvolvimento real caracteriza o desenvolvimento mental retrospectivamente, enquanto a zona de desenvolvimento proximal caracteriza o nível de desenvolvimento mental prospectivamente" (Vigotski, 2007, p. 98).

Sendo assim, desenvolver o jogo com outros colegas, poderia ser um grande incentivo à aprendizagem de Marcos. Considerando as reações de agressividade observadas, os encontros foram realizados inicialmente entre Marcos e a pesquisadora, em seguida, inserindo a participação das crianças da turma que foram autorizadas, uma por vez, visando diminuir as chances de que o comportamento ocorresse no espaço destinado à atividade, zelando pela integridade física e emocional de todos os sujeitos.

Os encontros para promoção do jogo aconteceram preferencialmente no horário das aulas de matemática, mas fora da sala de aula, em horários combinados previamente com a professora a fim de não interferir negativamente na dinâmica da turma. A monitora participou apenas do primeiro contato da pesquisadora com o sujeito e nos momentos em sala de aula. Na realização do jogo foi pretendido que as observações ocorressem sem essa interferência. Esses momentos tiveram duração aproximada de 40 a 50 minutos.

\section{Resultados e Discussão}

O jogo foi realizado sempre em duplas, primeiramente entre Marcos e a pesquisadora e depois convidando as outras crianças autorizadas e escolhidas por ele. Em todas as etapas foi considerado, para além das deficiências que caracterizam a síndrome, suas possibilidades

Ao apresentar a BOA, mesmo tendo em conta as perdas na memória verbal de curto prazo, foi valorizada a preservação da memória visuoespacial, com os recursos indicados na Figura 2.

Figura 2: Marcos contando as bolinhas indicadas nos dados, para pegar os respectivos palitos

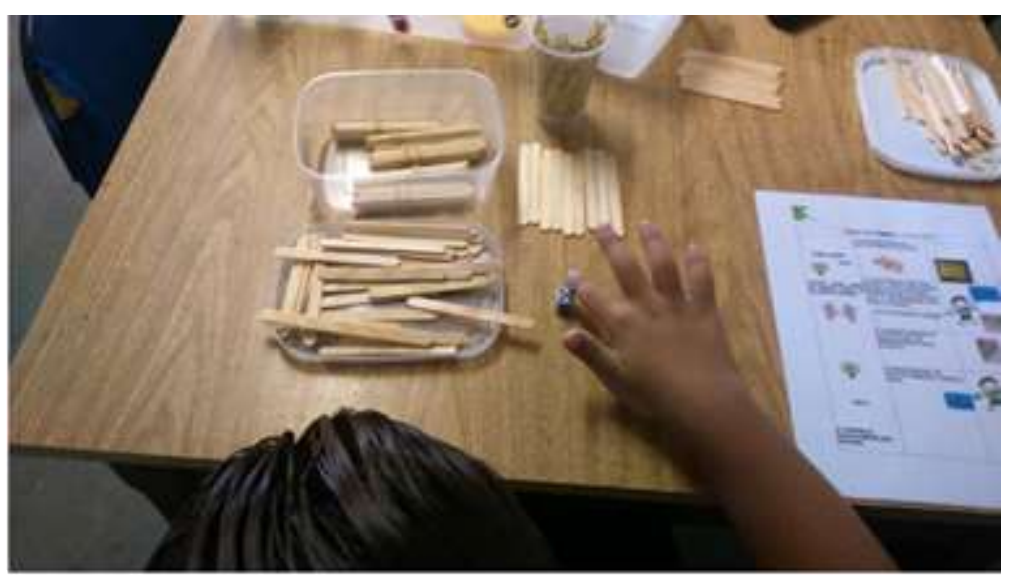

Fonte: Corrêa, (2017, p. 90).

Para estimulá-lo em relação a esse aspecto foram utilizadas fichas com as instruções escritas, materiais para manipulação e a representação desses materiais através de desenhos. A formação do aspecto material da ação ocorreu com apoio dos materiais manipulativos disponibilizados para os estudantes: dados, palitos, ligas elásticas, potes e fichas que foram organizados numa caixa identificada como caixa matemática. Durante a manipulação Marcos precisava contar, relacionar a quantidade de objetos indicadas pelas bolinhas dos dados. 
Nas situações de contagem que ocorriam nos primeiros encontros, Marcos "pulava" alguns números, ou alternava sua afirmação dizendo que em um momento 100 palitos representavam muitos palitos e em outro momento, considerando a mesma quantidade, ele afirmava que eram poucos palitos. Isso indicava que o conceito de número ainda não estava consolidado por ele, pois ainda não estabelecia a relação termo a termo.

Na história da humanidade, como apresenta Caraça (1951), os números só surgem para resolver problemas de contagem. Dessa forma, o jogo "Ganha 100 Primeiro" criou a necessidade da contagem devido à relação entre os jogadores, pois esse jogo somente tem razão de ser se realizado coletivamente (Corrêa, 2017, p. 91).

Durante a contagem para alcançar os objetivos do jogo, Marcos foi estimulado a vivenciar essa necessidade e se apropriar do conceito de número. Ao longo das jogadas, quando obtinha os 10 palitos passou a pegar a liga elástica para realizar o agrupamento. "[...] Marcos junta os palitos sozinho, reconhecendo qual ação precisava realizar sem que a pesquisadora dissesse o que deveria ser feito ou precisasse recorrer à BOA" (Corrêa, 2017, p. 93).

Uma das contribuições de Castro e Drago (2013) refere-se à importância dos estímulos para o desenvolvimento da linguagem. O jogo foi adaptado para que também gerasse a necessidade de verbalização, especialmente pela presença da dupla. Além da contagem em voz alta, quando um jogador conclúáa a sua rodada, ele precisa falar para o outro "Eu te autorizo a jogar!". Durante o jogo essa frase foi simplificada para "Pode jogar!".

Para avançar no aspecto linguístico da ação, as verbalizações eram incentivadas a todo momento. Uma das estratégias planejadas foi realizar o jogo primeiramente entre a pesquisadora e Marcos, a fim de que ele, ao aprender como se joga, fosse estimulado a ensinar o jogo para os colegas da sala quando estes fossem convidados a participar.

Um aspecto presente na primeira parte da pesquisa, foi a lentidão com que Marcos realizava cada proposta: jogar os dados, contar oralmente, responder às perguntas, fazendo com que a demanda de tempo para realização do jogo fosse superior ao previsto. Passavam-se os quarenta ou cinquenta minutos e o jogo não era concluído.

Marcos foi estimulado a participar ativamente e escolher quem jogaria com ele. Esta foi uma estratégia para valorizar sua escolha. O momento da participação de um colega da turma intencionou verificar se a presença das crianças de desenvolvimento típico representaria estímulo extra à aprendizagem de conceitos matemáticos pelo estudante com síndrome de Down. Não se tinha ideia de como seria a reação de Marcos com o colega sem a monitora, sem a professora, apenas com a pesquisadora. Haveria algum comportamento agressivo?

"No dia da primeira participação de André, a reação de Marcos foi realmente surpreendente, pois ele passou a apresentar comportamento mais responsivo, demonstrou mais motivação e apresentou novas estratégias [...]" (Corrêa, 2017, p. 95). A lentidão que marcou a primeira fase da atividade foi substituída pela agilidade com a qual jogava os dados, verbalizava a contagem, pegava os palitos e agrupava-os com a liga elástica.

Os objetivos do jogo eram desafiadores para Marcos e André, pois ambos queriam ganhar o jogo e para isso ocorrer precisavam obter os palitos através dos dados. André acompanhava atentamente os movimentos de Marcos e, espontaneamente, pedia para ele conferir a contagem, como na Figura 3. 
Figura 3: André acompanha a jogada de Marcos

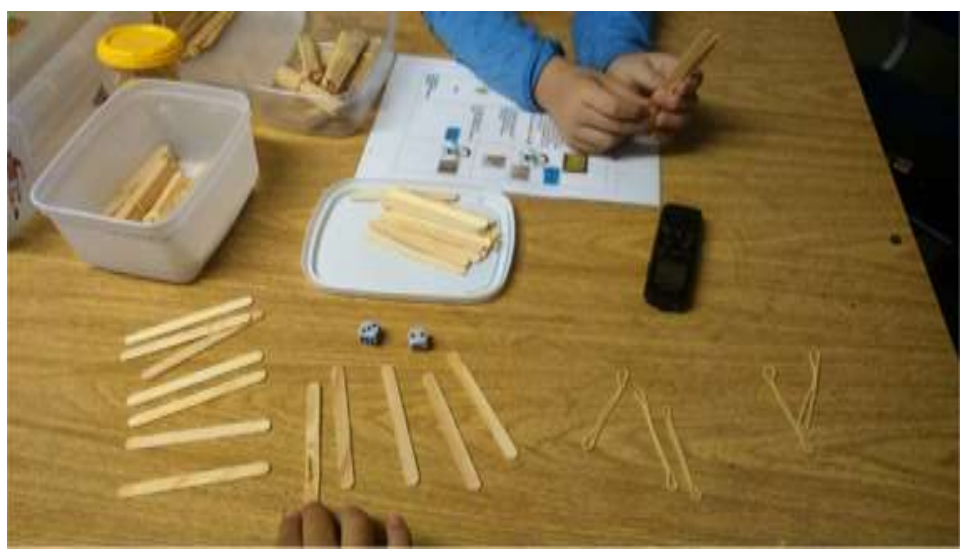

Fonte: Corrêa, (2017, p. 91).

$\mathrm{Na}$ imagem, e durante todas as rodadas do jogo, o comportamento de Arthur indicou que estava divertindo-se com Marcos e dispensava atenção genuína ao colega.

Marcos também observava as atitudes de André e começou a imitar seu comportamento em relação à contagem. Passou a recitar os números em tom mais alto e com maior rapidez. No final da jogada começou a diminuir a verbalização, assim como André fazia, apenas tocando os palitos e indicando o resultado no final, sugerindo avanço na relação termo a termo, que caracteriza o conceito de número.

Outro dado importante é que o encontro com o colega aconteceu no final do turno escolar e em apenas trinta minutos o jogo foi realizado completamente.

A postura de ambos durante o deslocamento para a sala de aula, conforme observado na Figura 4, é uma indicação da satisfação por estarem juntos.

Figura 4: Marcos e André voltando para sala de aula.

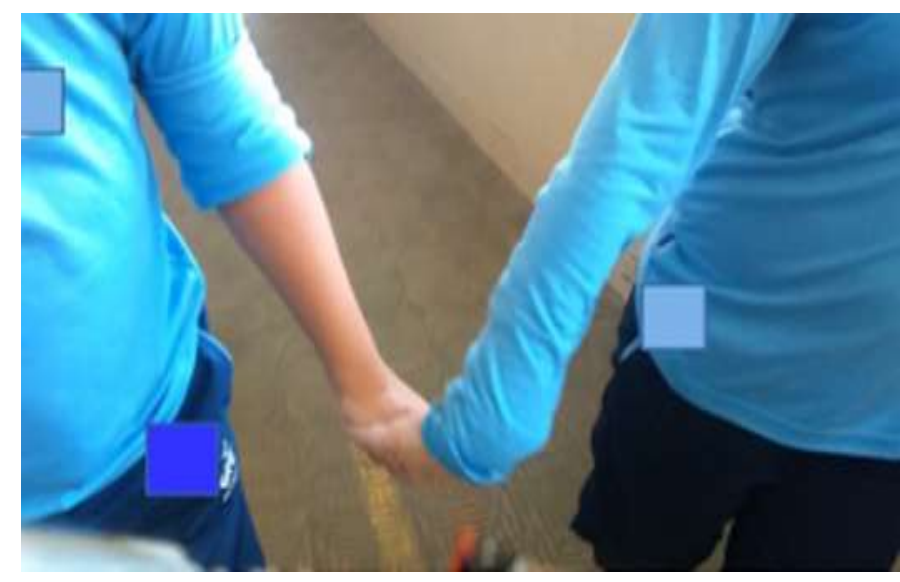

Fonte: Corrêa, (2017, p. 83).

A preocupação com o surgimento de conflitos foi dirimida durante toda atividade, pois Marcos e André jogaram como duas crianças que se alegram juntas diante de desafios.

O procedimento alcançou êxito em todos os aspectos, pois como sugerido por Castro e Drago (2013), a valorização da capacidade de imitação de comportamentos e atitudes presente nos sujeitos com síndrome de Down, possibilitou o aprender com os pares no dizer dos autores, sendo estratégia fecunda para a aprendizagem matemática. 


\section{Considerações Finais}

A vivência da atividade entre Marcos e os colegas proposta por Corrêa (2017), trouxe contribuição importante para a aprendizagem matemática do sujeito com síndrome de Down, em um ambiente de ludicidade e parceria.

Estratégias que não privilegiam as habilidades intelectuais para realização da atividade, como no caso do jogo adaptado por Corrêa e Thiengo (2017), possibilitaram maior interação e motivação entre todas as crianças envolvidas, independente da síndrome de Down, indicando caminhos para promoção da inclusão da pessoa com deficiência na escola regular e trazendo benefícios para todos.

Com efeito, é preciso considerar que a formação do profissional de educação seja um dos fatores importantes para a qualidade da aprendizagem dos estudantes, na promoção de atividades que, além de considerar as deficiências, valorizem as potencialidades.

Embora assegurado o direito à inclusão, seja por meio dos insumos jurídicos ou pedagógicos, a subjetividade da ação docente deve ser considerada para que a efetivação das premissas inclusivas se torne práxis no cotidiano dos processos ensinoaprendizagem. Incluir é garantir o respeito às diferenças, com equidade e justiça, de forma a promover a socialização e o desenvolvimento social, cultural e cognitivo dos alunos que dela dependem para prosseguir em seus processos de aprendizagem.

Os resultados positivos obtidos com esta pesquisa indicam a necessidade da continuidade de investigações no caminho da aprendizagem matemática do sujeito com síndrome de Down.

A realização da pesquisa em um tempo maior, envolvendo um número maior de estudantes com síndrome de Down em cooperação com crianças de desenvolvimento típico, poderá oferecer mais informações para avaliar os benefícios do trabalho entre pares na aprendizagem matemática dos sujeitos com síndrome de Down.

\section{Referências}

Bissoto, M. L. (2005). Desenvolvimento cognitivo e o processo de aprendizagem do portador da Síndrome de Down: revendo concepções e perspectivas educacionais. Ciência \& Cognição, 4, 80-8. http://www.cienciasecognicao.org/revista/index.php/cec/article/view/514/284.

Brasil. (2014). Ministério da Educação. Pacto Nacional pela Alfabetização na Idade Certa: Construção do Sistema de Numeração Decimal, caderno 03, 47 - 78, Brasília: MEC/SEB.

Castro, M. G. L. de., \& Drago, R. (2013). Síndrome de Down: características e possibilidades de inclusão nas salas de aula da escola comum. In: Drago, R., Pantaleão, E. \& Victor, S. L. (org.). Educação Especial: Indícios, registros e práticas de inclusão. São Carlos: Pedro \& João Editores.

Corrêa, G. de A. (2017). Apropriação do conceito de sistema de numeração decimal por uma criança com síndrome de Down na perspectiva da teoria da formação planejada das ações mentais. Vitória. https://repositorio.ifes.edu.br/xmlui/handle/123456789/245.

Corrêa, G. de A., \& Thiengo, E. R. (2017). Jogos do Sistema de Numeração Decimal para Crianças com Síndrome de Down: jogo 1: ganha 100 primeiro. (1 ${ }^{\mathrm{a}}$ edição): Editora IFES. https://educapes.capes.gov.br/handle/capes/564160.

Franzoi, M., Granziol, U., Mento, G., Lanfranchi, S., \& Scerif, G. (2020) The Effect of Probabilistic Context on Implicit Temporal Expectations in Down Syndrome. Frontiers Psychology. vol.11. https://www.frontiersin.org/articles/10.3389/fpsyg.2020.00369/full.

Galperin, P. Y. (2013). A formação dos conceitos e das ações mentais. Revista Amazônica. Universidade Federal do Amazonas. 11(2) 440-50. Julh-Dez. https://dialnet.unirioja.es/servlet/articulo?codigo $=4730780$.

Gil, A. C. (2008). Métodos e Técnicas de Pesquisa Social. São Paulo: Atlas, (6 a ed.)

Mazzotta, M. J. S. (2011). Educação especial no Brasil: histórias e políticas públicas. (5ª .ed.): Cortez.

Mendes, E. G. (2010). Breve histórico da Educação Especial no Brasil. Revista Educacion y Pedagogia, Medellín, 22(57), 93-109, may/ago.

Michels, M. M., \& Lehmkuhl, M. S. (2016). Movimentos sociais e educação especial: reflexões a partir de um balanço de produção. In: Reunião Científica Regional da Associação Nacional de Pós-Graduação e Pesquisa em Educação. Curitiba/PR. Anais Eletrônicos Curitiba: ANPED.

Muniz, C. A., et al. (2014). Agrupamentos e Trocas. In: Brasil. Ministério da Educação. Pacto Nacional pela Alfabetização na Idade Certa: Construção do Sistema de Numeração Decimal, caderno 03, 27-32. Brasília: MEC/SEBE. https://bitlybr.com/rIHDtciK.

Muniz, C. A., et al. (2014). O corpo como fonte do conhecimento matemático. In: Brasil. Ministério da Educação. Pacto Nacional pela Alfabetização na Idade Certa: Construção do Sistema de Numeração Decimal, caderno 03, 10-3. Brasília: MEC/SEBE. https://bitlybr.com/rIHDtciK. 
Research, Society and Development, v. 10, n. 12, e437101220783, 2021

(CC BY 4.0) | ISSN 2525-3409 | DOI: http://dx.doi.org/10.33448/rsd-v10i12.20783

Muniz, C. A., et al. (2014). O lúdico, os jogos e o SND. In: Brasil. Ministério da Educação. Pacto Nacional pela Alfabetização na Idade Certa: Construção do Sistema de Numeração Decimal, caderno 03, 14-8. Brasília: MEC/SEBE. https://bitlybr.com/rIHDtciK.

Núñez, I. B., \& Ramalho, B. L. (2017). A teoria da Formação Planejada das Ações Mentais e de Conceitos de P. Ya Galperin: contribuições para a Didática Desenvolvimental. Obutchénie - Revista de Didática e Psicologia Pedagógica, 1-29. Urbelândia, MG.

Passos, C. L. B. (2004). Materiais manipuláveis como recursos didáticos na formação de professores de matemática. In: Lorenzato, S. (org.). O Laboratório de ensino de matemática na formação de professores. Campinas: Autores Associados.

Rogalski, S. M. (2010). Histórico do surgimento da educação especial. Revista de Educação do IDEAU, Rio Grande do Sul, 05(12), 2-13, jul./dez.

Sassaki, R. K. (2012). Causa impedimento, deficiência e incapacidade, segundo a inclusão. Revista Reação, São Paulo, ano XIV, n.87, 14-6, jul./ago.

Schwartzan, J. S. (1999). Síndrome de Down. São Paulo: Mackenzie.

Silveira, L. V., \& Drago, R. (2010). A educação da criança com deficiência: da segregação às propostas inclusivas. Revista FACEVV, Vila Velha, 4, 82-9, jan./jun.

Silva, L. C. da. (2015). Formação de professores: desafios à educação inclusiva. Revista Ibero-Americana de Estudos em Educação, Araraquara, 10(esp.1), 691702 .

Vigotski, L. S. (2005). Pensamento e Linguagem. Tradução Camargo, J. L. - (3 ${ }^{\mathrm{a}}$ ed.): Martins Fontes.

Vigotski, L. S. (2007). A formação social da mente: o desenvolvimento dos processos psicológicos superiores. Org. Cole, M. et al. Tradução Afeche, S. C. et al., (7 $7^{\mathrm{a}}$ edição): Martins Fontes. 